\title{
The Early History of Fisheries Management in Michigan w. c. Latta
}

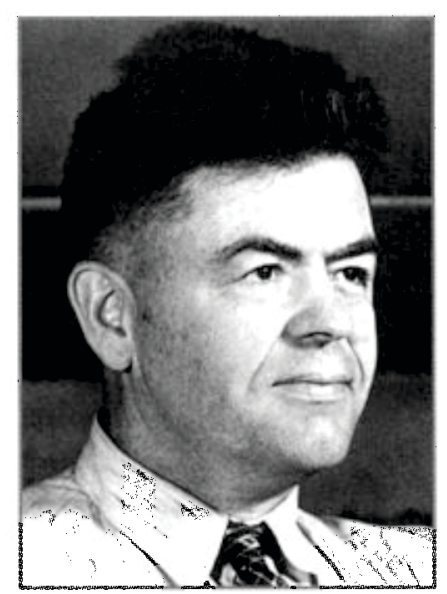

Carl L. Hubbs, 1894-1979

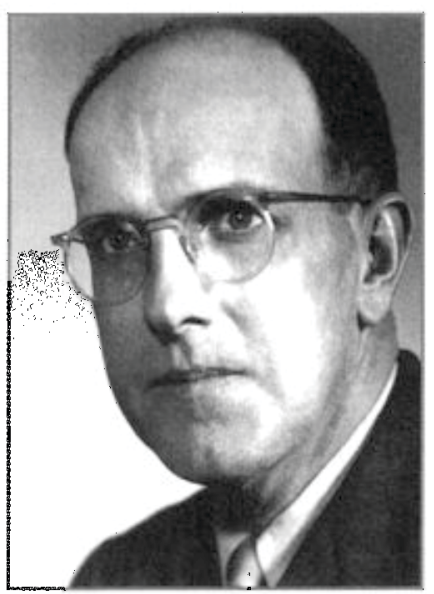

Albert S. Hazzard, 1901-1979

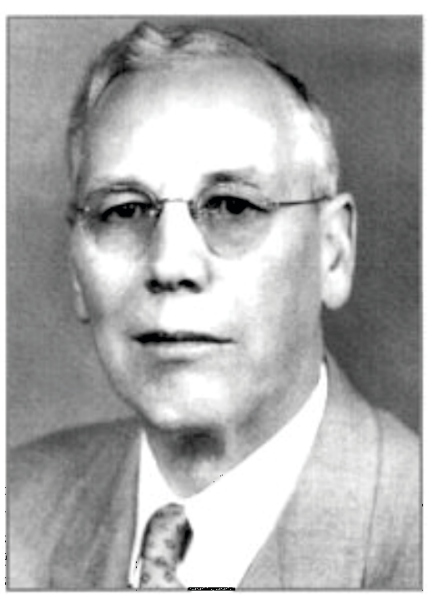

Fred A. Westerman, 1890-1985
ABSTRACT: The culture and stocking of fish in North America began in the last half of the nineteenth century. Fish culture was seen as a way to bolster the realized decline of fish populations, but also as a way to introduce new species thought to be desirable to all waters. A private brook trout hatchery was started in Clarkston, Michigan in 1867, and the state of Michigan built their first hatchery in Pokagon in 1873. The enthusiasm for stocking was eventually tempered with the realization that more knowledge was needed about the life history requirements of the fishes and the waters where they lived. Regulation of the fisheries had also begun. In 1920, Carl L. Hubbs, who became a noted ichthyologist, was hired at the Latta, retired director of fisheries research and head of the Institute for Fisheries Research at the Michigan Department of Natural Resources, is an adjunct research scientist in the School of Natural Resources and Environment University of Michigan, Ann Arbor. $\mathrm{He}$ can be reached at clatta@umich.edu. University of Michigan. In 1930, he founded the Institute for Fisheries Research. The founding of the institute was a pivotal point in the development of fisheries management. In the next 15 years in Michigan, essentially all of the concepts of fisheries management were put into practice and evaluation was done. In 1935, Hubbs hired Albert S. Hazzard to be a full-time director of the institute. Hazzard had a Ph.D. in zoology from Cornell University and had worked as an aquatic biologist for the U.S. Bureau of Fisheries in the western United States. The third key person responsible for the advances in fisheries in Michigan was Fred A. Westerman, chief of the Michigan Department of Conservation, Fisheries Division, from 1925-1959. Westerman, who had little education beyond high school and grew up in the Michigan hatchery system, provided agency support. Hubbs assembled a group of bright graduate students, and this trio of leaders in 1930-45 utilized the students to do pioneering work in the field of fisheries management. They used an inventory of streams and lakes to determine suitable management methods, developed and evaluated lake and stream improvement methods, used the creel census to measure game fish yield, analyzed stream and lake fish populations, determined the success of different methods of planting, and initiated studies of fish migration, growth rates, food habits, fish predators, use of the piscicide rotenone, spawning habits of the common fishes, and relationships of principal game and forage fishes.

\section{INTRODUCTION}

Management of fish populations in the freshwaters of North America utilizes culturing and stocking fishes, inventorying fishes in concerned waters, protecting and creating of suitable habitats for fishes, and manipulating fish populations with nets, piscicides, or regulations. From 1930 through 1945, most of these management practices, which succeeded the culturing and stocking of fishes, were recognized and applied in Michigan. The nucleus for change was provided by the establishment of the Institute for Fisheries Research, a coopera- tive effort between the University of Michigan and the Michigan Department of Conservation, administered and supported by pioneering fisheries leaders during this era. The objective here is to document the fisheries management practices and individuals involved in these changes.

\section{EARLY HISTORY}

In 1853, Theodatus Garlick, in Ohio, demonstrated that salmonids could be propagated artificially, and by 1864 Seth Green in Caledonia, New York, opened a commercial trout hatchery (Wood 1953; Thompson 1970). 
In 1867, N. W. Clark started a private brook trout hatchery at Clarkston in Oakland County, Michigan, followed in 1874 with another at Northville. The state of Michigan's first hatchery was built in 1873 at Pokagon, near Niles, Cass County (Westers and Stauffer 1974).

Culture of fish was seen as a way to bolster the realized decline of fish populations but also as a way to introduce new species thought to be desirable to all waters. At the Pokagon hatchery in 1874 , in addition to the propagation of lake whitefish (Coregonus clupeaformis), a Great Lakes native fish, Atlantic salmon

(Salmo salar) from the East Coast and king salmon (Oncorhynchus tshawytscha) from West Coast were raised. During these early years the common carp (Cyprinus carpio), a species now realized to be detrimental to most management goals, was being stocked nationwide. In Michigan, the stocked salmon did not survive but, of course, the carp did. In 1870, a group of fish culturists gathered in rooms of the New York Poultry Society to form an organization entitled The American Fish Culturists Association. Its goal was to share information on "the cultivation of fish for scientific as well as for economic purposes" (Thompson 1970). However, the early proceedings also reported concerns about pollution, over-netting, dams, siltation, and other detriments to fish and fishing. In 1886, the association became the present day American Fisheries Society. The enthusiasm for stocking was eventually tempered with the realization that more knowledge was needed about the life history requirements of the fishes and waters where they lived. Regulation of fisheries also was begun during the last half of the nineteen century (for Michigan, see Borgeson 1974) but depletion of fish stocks continued. In Michigan, this new biological awareness was reflected in the Michigan Fish

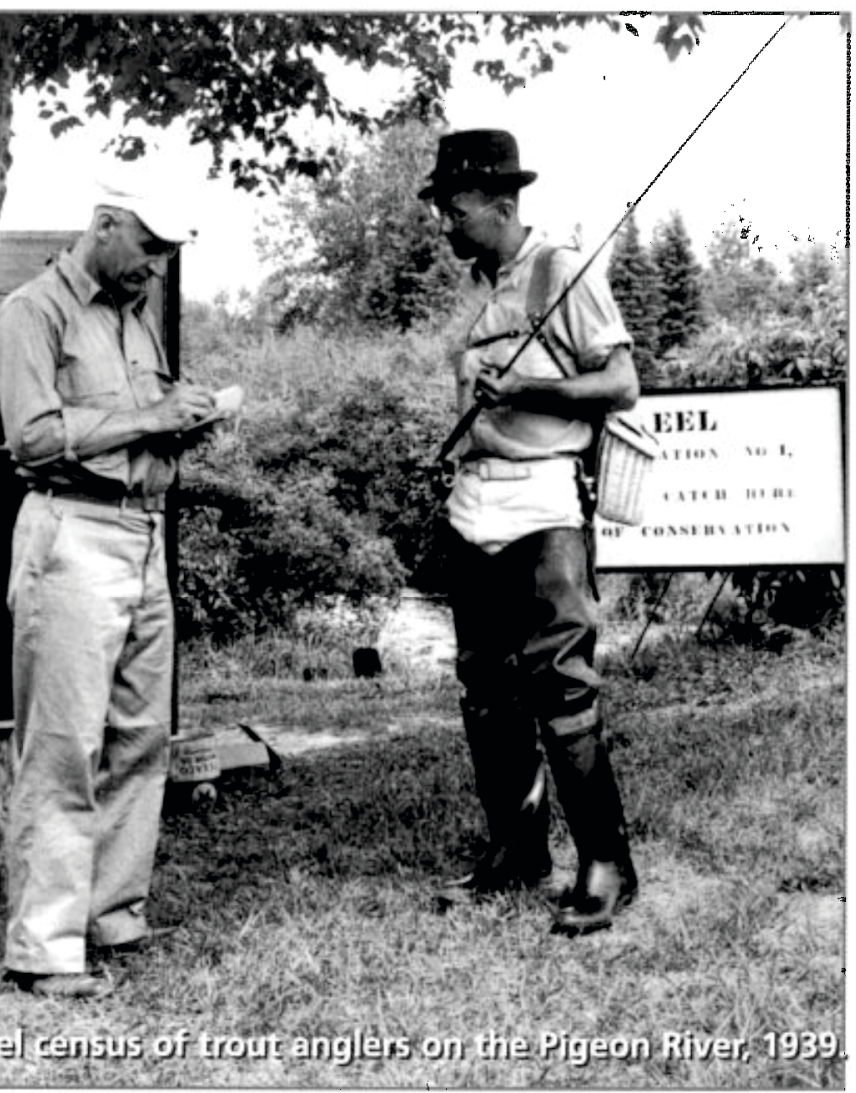

The founding of the Institute for Fisheries Research was a pivotal point in the development of fisheries management in Michigan and the country. In the next 15 years in Michigan, essentially all of the concepts of modern fisheries management were put into practice and evaluation was begun. With the origin of the institute, Hubbs, at the 1930 meeting of the American Fisheries Society, listed the initial research activities: (1) creel census of sport fishing, (2) lake and stream surveys, (3) modifying conditions in natural waters (lake and stream improvement), (4) nursery waters (recognition and pro-

Commission hiring, at the turn of the century, Professor Jacob E. Reighard of the University of Michigan to do studies of fish and their environment. In the Fish Commission's 11th biennial report (1894), Reighard published a biological examination of Lake St. Clair and, in the 16th biennial report (1905), he published a study of the breeding habits, development, and propagation of black bass (Micropterus salmoides and M. dolomieu; Taube 1974).

Stocking, regulation, inventory, and life history studies of fishes were being done when Carl L. Hubbs was hired, in 1920 , to be curator of fishes at the University of Michigan. Hubbs, who became a giant in the field of ichthyology, was educated at Stanford University (Norris 1974). He was the last graduate student of David Starr Jordan, then president of Stanford and the preeminent ichthyologist in North America. Hubbs, whose interests in fishes were broad, was knowledgeable about management as well as systematics. In 1930, he founded the Institute for Fisheries Research with the financial support of the Michigan Department of Conservation and a subsidy from the Michigan Division of the Izaak Walton League (Hubbs 1964). tection), (5) migration studies, (6) predator studies (depleting stocks), (7) fish diseases (in hatcheries and nature), (8) fish survey (distribution of species in the state), (9) dwarfing analysis (growth of yellow perch Perca flavescens), and (10) growth investigations (growth rates, age, maturity, methods, and hybrids).

Hubbs, as energetic and as bright as he was, probably would not have accomplished as much without the help of two others. After directing the institute for five years, as well as fulfilling his university obligations, Hubbs hired Albert S. Hazzard, in 1935, as a full-time director. Hazzard, with a Ph.D, in zoology from Cornell University, had been working as an aquatic biologist for the U.S. Bureau of Fisheries in the inter-mountain region of the West. He became president of the American Fisheries Society in 1950-51, and in 1955, left Michigan to become assistant executive director of the Pennsylvania Fish Commission, a position he held until his retirement in 1963 (Cooper 1979).

The third key person responsible for advances in Michigan was Fred A. Westerman, chief of the Michigan Department of Conservation Fisheries Division from 1925-1959. Westerman grew up in the Michigan hatchery system. 
He worked on the family farm near Paris, Michigan, substituted as a rural mail carrier, and attended Ferris Institute (now Ferris State University) three winters until he got a job as a laborer at the Harrietta Hatchery in 1913 (Taube 1974). His father worked at the Paris Hatchery and eventually became overseer at the Harrietta Hatchery. Westerman rose in hatchery employment to became superintendent of the railroad fish car "Wolverine" that transported fish to be stocked throughout the state, overseer of the Harrietta Hatchery (replacing his father), and then chief of the Fish Division. Although only hatchery trained, he recognized the need for research in fisheries, financially supported the beginning of the institute, and increased the support to hire Hazzard as a full-time director. He too was active in the American Fisheries Society, of which he was president in 1933-1934.

With the establishment of the institute, Carl Hubbs recruited as early graduate students J. Clark Salyer, Clarence M. Tarzwell, R. W. Eschmeyer, Gerald P. Cooper, Justin W. Leonard, David S. Shetter, William F. Carbine, Karl F. Lagler, William C. Beckman, John T. Greenbank, Robert C. Ball, and others, all of whom contributed significantly to fisheries research and went on to distinguished careers in aquatic science, teaching, and administration of fisheries across the United States. Hubbs left the University of Michigan in 1944 for the Scripps Institution of Oceanography where he immersed himself, as was typical of the man, in the study of marine fishes and such things as grey whales and aboriginal habitations in southern California and Baja California. At his death in 1979, he had a bibliography of 700 publications (Shor 1980).

The first publication of the Institute for Fisheries Research (Bulletin No. 1) entitled "Methods for the Improvement of Michigan Trout Streams" came out in 1932. Stream improvement was recognized as the final step in trout management following introduction, propagation, and protection. This technique addressed improving fish habitat with the addition of dams, deflectors (of stream flow), and cover. The authors were Hubbs, John R. Greeley, assistant director of the institute then and a recent Ph.D. from Cornell University, and Clarence $M$. Tarzwell, the first institute fellow to

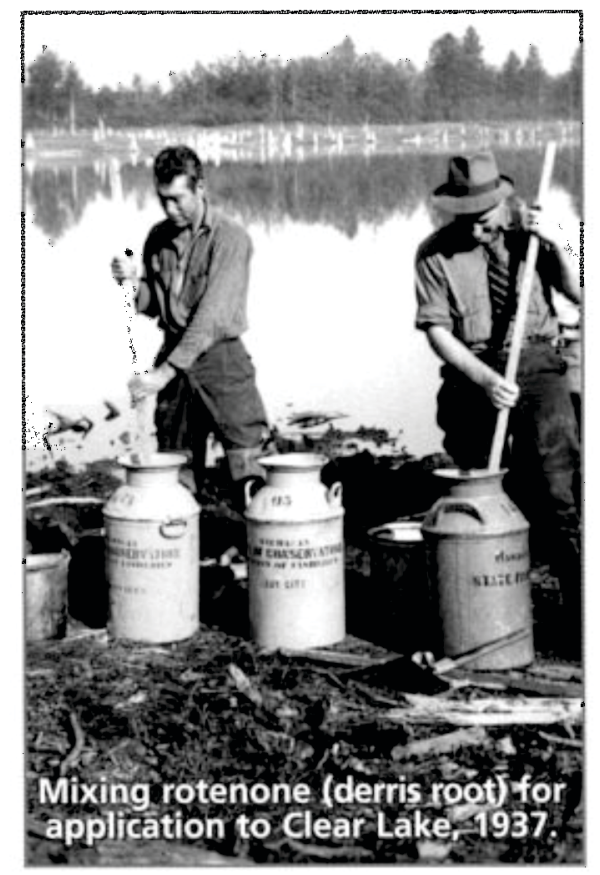

receive a Ph.D. at the institute. Although stream improvement was practiced in Great Britain, essentially none had been tried in the United States. The exception was work done by E. R. Hewitt on his private estate in New York (Hewitt 1931). At the time of publication of the bulletin, Tarzwell had under observation about 900 improvement devices. He was measuring such things as physical changes in the stream associated with the structures, changes in trout food present, and numbers of trout. His work was mostly on four trout streams. The authors acknowledged that the work in Michigan was on a large scale and "the first extensive work of this sort to be undertaken on a public trout stream anywhere" (Hubbs et al. 1932). In 1933, at the American Fisheries Society meeting, Seth Gordon, commenting on scientific fisheries management stated, "Up to the present time most of our information on stream and lake improvement is confined to the state of Michigan, where Dr. Hubbs and his staff have been doing such a fine job, and the private sources" (Gordon 1933).

In 1938, Hubbs and R. W. Eschmeyer published Institute Bulletin No. 2, "The Improvement of Lakes for Fishing." Eschmeyer was the second doctoral fellow at the institute to complete a Ph.D. His studies emphasized fish populations in lakes, particularly slow-growing or "stunted" yellow perch. This bulletin, primarily a "how-to-do-it" manual, discussed such things as lake inventories, creel census, addition of brush shelters and spawning areas, plant growths, removal of excess coarse fish, and control of predators. In the "Announcement" to this volume Hazzard stated, "Specific problems investigated by the institute, at the request of the department, at present include: further research into the methods and value of stream and lake improvement; inventory of the streams and inland lakes to determine suitable management methods; studies of migration, growth rate, food habits, spawning habits, and relationships of the principal game and forage fishes; determination of the game fish yield by creel censuses; analysis of fish populations; and appraisal of success of different methods of planting." In addition, cooperative studies were being done on fish nutrition and fish predators. Modern fish management had arrived.

A perusal of papers, technical and popular, published by the institute staff (mostly doctoral students) in 1930-1945, provides a record of fish management evaluations and techniques developed (Latta 1980). More than 150 titles are listed. This record adds substance to Hazzard's list. Three basic techniques essential in early fish management are described in this list. The first is the lake survey method. The New York State Conservation Department initiated systematic biological surveys of lakes and streams in 1926 (Carlander 1970); Michigan followed closely in 1930 with comprehensive lake surveys (McMurry et al. 1933).

The second is the creel census (Eschmeyer 1937). In this paper, Eschmeyer described the intensive census application and uses in fish management for individual lakes. Also, he cited the general statewide census conceived by Harold Titus, a member of the Michigan Conservation Commission, and implemented in 1927. In this census, conservation officers in their regular patrols obtained individual catch-per-hour records from contacted fishing parties on lakes and streams. The institute compiled the records.

The final technique is the use of rotenone, a piscicide, to remove, sample or manipulate fish populations (Ball 1948, accepted in 1945). Ball reported that rotenone was first used in the United States in 1934 by the institute to remove large populations of carp from two small ponds on the estate of W. O. Briggs, Birmingham, Michigan. In 1938, J. W. 
Leonard of the institute staff determined in the laboratory various lethal doses for different kinds, sizes, and habitats of fishes (Leonard 1939).

Other representative papers from 1936-1945 to consider are by Cooper (1936) on some forage fish investigations, Eschmeyer (1938) on fish population structure in lakes, Rodeheffer (1939) on the use of brush shelters in lakes by fish, Carbine (1939) on spawning habits of centrarchids, Hazzard and Shetter (1939) on experimental plants of legal-sized brook (Salvelinus fontinalis) and rainbow trout (Oncorhynchus mykiss), Salyer and Lagler (1940) on food habits of the American merganser during winter, Beckman (1941) on increased growth of rock bass (Ambloplites rupestris) with reduced density of fish, Shetter and Leonard (1943) on a population study of trout in a stream segment, and Greenbank (1945) on winter-kill of fish in lakes.

In 1939, the Hunt Creek Trout Research Station (first in the United States) was established in Montmorency County. Hunt Creek is a headwaters trout stream. At this site, creel census and estimates of trout population size were utilized to evaluate stocking scenarios and stream improvement techniques. Other biological questions about food and growth of trout were answered as well (Hazzard 1940; Leonard 1942; Shetter et al. 1949).

In 1945, Westerman and Hazzard published a booklet entitled "For Better Fishing!" with the subtitle of "Changing Policies and Practices in Michigan Fish Management." It documented the application of the 15 years of fisheries research, from the start of the Institute for Fisheries Research in 1930 to the date of the report 1945 , in replacing the stocking paradigm with a holistic or ecosystem approach to fisheries management. In the introductory essay of the booklet, Westerman stated, "Only in recent years has the proof become available of the actual value of improving the environment for fish, but the factual information already collected show that this is probably the most promising field of fish management." Two paragraphs later he highlighted what he labeled as a "revolutionary" statement which stated "The evidence to be presented later leads to the conclusion that stocking is unnecessary, uneconomical, or even harmful if the species suited to the environment are already present." The booklet is divided into three parts, the first addresses trout fishing, the second warmwater fishing (bass Micropterus spp., bluegills Lepomis macrochirus, etc.), and the third fish laws.

For trout fishing, numerous experiments in planting marked trout of fingerling or legal size, at different times of the year and in different streams, were completed to determine which planting combinations gave the best return to the angler. Westerman and Hazzard concluded that "in the great majority of Michigan streams, otherwise suitable for trout, enough or more than enough young are produced to fully seed the waters with all the fish which they can feed and house."

In the warmwater fish management section the authors acknowledged, as they did for trout, the necessity of biological surveys to determine the kinds of fish and types of lakes to manage. They distinguished between stocking for introduction and stocking for maintenance. They noted that the indiscriminate stocking in the past created new populations and fisheries in some waters but that those opportunities were few in the present. They stated, "Planting of fingerling bass, bluegills, perch Perca flavescens, pikeperch Sander vitreus and other warm-water fish in waters now containing them is believed to be valueless or actually harmful." This statement was supported by discussions of the following points: "(1) Large number of young fish produced by natural spawning; (2) Large number of breeders even in heavily fished lakes; (3) Ability to spawn in varied habitats and (for bluegills) extended spawning season; (4) Evidence from growth studies [growth density dependent]; (5) Good fishing and no lack of small fish in spite of no stocking; (6) Danger of introducing parasites and disease; and (7) Planting not needed 'to bring in new blood." They finished this

\section{A lake survey to test water chemistry on BawBeese Lake, 1931.}

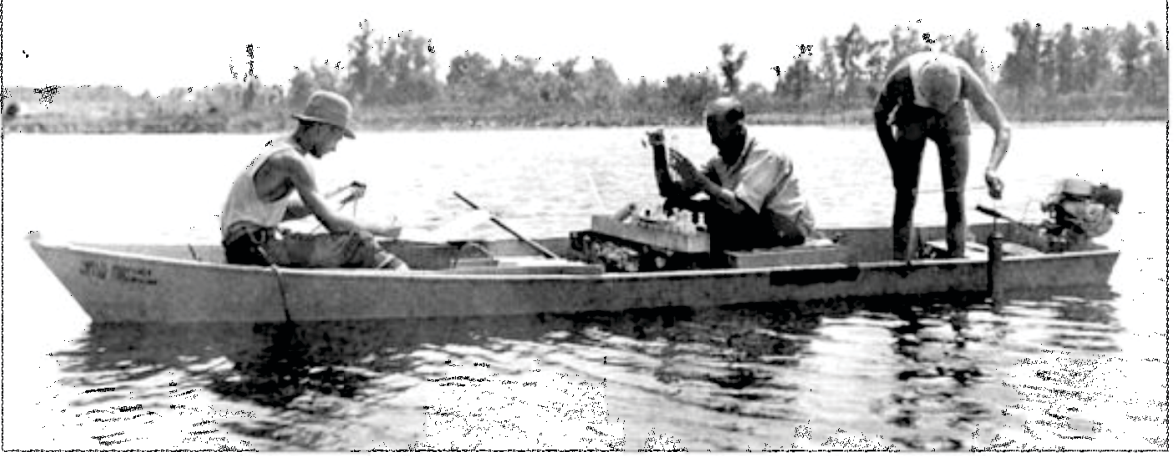

part with comments on the value and practicability of the use of fertilization, brush shelters, and population control to manage lake fish populations.

In the final segment on fish laws they discuss open seasons, size limits, daily limits, and methods of fishing for trout. Fly-fishing-only and catch-and-release fishing are suggested for some situations. For warmwater regulations, the same restrictions are discussed. They propose no substantial changes except that the size limit should be abolished on "perch, bluegills, sunfish Lepomis spp., rock bass, crappies Pomoxis spp., etc." but not on the "predatory game fish" such as "bass, pike Esox lucius, muskellunge Esox masquinongy and pikeperch."

\section{CONCLUSIONS}

Michigan played an active part in the development of fisheries management. Papers published by Michigan biologists during those years contained few citations from other parts of the country. The investigations were original and there was little other published information. Judging from their writings, Hubbs provided the energy and ideas, Westerman recognized the need for fisheries research and provided the agency support to accomplish this goal, and Hazzard was able to implement and carry to fruition the pioneering studies. These outstanding individuals should be recognized as three of the leaders in the development of modern fisheries management.

Although today the practice and research of fisheries management is significantly more sophisticated, the ideas have not changed from those early years. The conclusions reached in these first studies may no longer be completely valid but as in all good science the building blocks were laid. 


\section{ACKNOWLEDGMENTS}

I want to thank Elizabeth M. HayChmielewski and James E. Breck, fisheries biologists at the Institute for Fisheries Research, Fisheries Division, Michigan Department of Natural Resources for editing and reviewing the manuscript. And a special thank you to Robert C. Ball, Paul H. Eschmeyer, and Mercer H. Patriarche, fisheries biologists who, in the past, participated in or were close to the era considered in this account, for their editing and comments. Thanks also to the editors and reviewers of Fisheries for their comments and suggestions. Michelle Leung and Mike Rozenfeld, state fisheries workers, did the word processing. Tina M. Tincher, librarian, helped greatly with the literature retrieval. Ellen S. G. Johnston provided invaluable assistance with the final draft. Alan D. Sutton prepared the photos.

\section{REFERENCES}

Ball, R. C. 1948. A summary of experiments in Michigan lakes on the elimination of fish populations with totenone, 1934-42. Transactions of the American Fisheries Society 75(1945):139-146.

Beckman, W. C. 1941. Increased growth rate of rock bass, Ambloplites rupestris (Rafinesque), following reduction in the density of the population. Transactions of the American Fisheries Society 70:143-148.

Borgeson, D. P. 1974. Michigan sport fishing regulations, 1820-1973. Pages 67-74 in Michigan Fisheries Centennial Report, 1873-1973. Michigan Department of Natural Resources, Fisheries Management Report 6, Lansing.

Carbine, W. F. 1939. Observations on the spawning habits of centrarchid fishes in Deep Lake, Oakland County, Michigan. Transactions of the 4th North American Wildlife Conference:275. 287.

Carlander, K. D. 1970. Fishery education and training. Pages 57-69 in N. G. Benson, ed. A century of fisheries in North America. American Fisheries Society Special Publication 7.

Cooper, G. P. 1936. Some results of forage fish investigations in Michigan. Transactions of the American Fisheries Society $65: 132-142$.

1979. In memoriam, Albert Sidney Hazzard, 1901-1979. Fisheries 4(2):59. 60.

Eschmeyer, R. W. 1937. The Michigan creel census. Transactions of the 2 nd North American Wildlife Conference: 625-634.
1938. The significance of fish population studies in lake management. Transactions of the 3rd North American Wildlife Conference: 458468.

Gordon, S. 1933. Scientific managementour future fisheries job. Transactions of the American Fisheries Society 63:73-79.

Greenbank, J. T. 1945. Limnological conditions in ice-covered lakes, especially as related to winter-kill of fish. Ecological Monographs 15:343392.

Hazzard, A. S. 1940. Hunt Creek fisheries experiment station. Michigan Conservationist $9(7): 4-5$.

Hazzard, A. S., and D. S. Shetter. 1939. Results from experimental plantings of legal-sized brook trout (Salvelinus fontinalis) and rainbow trout (Salmo irideus). Transactions of the American Fisheries Society 68:196-210.

Hewitt, E. R. 1931. Better trout streams, their maintenance with special reference to trout habits and food supply. Charles Scribner's Sons, New York.

Hubbs, C. L. 1930. Fishery research in Michigan. Transactions of the American Fisheries Society 60:182-186. 1964. History of ichthyology in the United States after 1850. Copeia $1964(1): 42-60$

Hubbs, C. L., and R. W. Eschmeyer. 1938. The improvement of lakes for fishing. Michigan Department of Conservation, Institute for Fisheries Research Bulletin 2, Ann Arbor.

Hubbs, C. L., J. R. Greeley, and C. M. Tarzwell. 1932. Methods for the improvement of Michigan trout streams. Michigan Department of Conservation, Institute for Fisheries Research Bulletin 1, Ann Arbor.

Latta, W. C. 1980. Institute for Fisheries Research 1930-1980, fifty years of fisheries investigations. Michigan Department of Natural Resources, Fisheries Division, Fisheries Research Report 1882, Ann Arbor.

Leonard, J. W. 1939. Notes on the use of derris as a fish poison. Transactions of the American Fisheries Society 68:269. 280.

1942. Some observations on the winter feeding habits of brook trout fingerlings in relation to natural food organisms present. Transactions of the American Fisheries Society 71:219-227.

McMurry, K. C., R. W. Eschmeyer, and C. M. Davis. 1933. Objectives and methods in the lake inventory in Michigan. Papers Michigan Academy of Science, Arts, and Letters 18:259-276.
Norris, K. S. 1974. To Carl Leavitt Hubbs, a modern pioneer naturalist on the occasion of his eightieth year. Copeia 1974(3):581-594.

Reighard, J. E. 1894. A biological examination of Lake St. Clair. Bulletin of the Michigan Fish Commission 4.

1905. The breeding habits, development and propagation of the black bass (Micropterus dolomieu Lacepede and Micropterus salmoides Lacepede). Bulletin of the Michigan Fish Commission 7.

Rodeheffer, J. A. 1939. Experiments in the use of brush shelters by fish in Michigan. Papers Michigan Academy of Science, Arts, and Letters 24 (part II): 183-193.

Salyer, J. C., II, and K. F. Lagler. 1940. The food and habits of the American merganser during winter in Michigan, considered in relation to fish management. Journal of Wildlife Management 29 (1):41-44.

Shetter, D. S., O. H. Clark, and A. S. Hazzard. 1949. The effects of deflectors in a section of a Michigan trout stream. Transactions of the American Fisheries Society 76 (1946):248-278.

Shetter, D. S., and J. W. Leonard. 1943. A population study of a limited area in a Michigan trout stream, September, 1940. Transactions of the American Fisheries Society 72:35-51.

Shor, E. N. 1980. In memoriam, Carl Leavitt Hubbs. California Cooperative Oceanic Fisheries Investigations, Reports 21:5.

Taube, C. M. 1974. Biographical profiles, persons notably engaged in Michigan's fisheries. Pages 153-177 in Michigan Fisheries Centennial Report 1873-1973. Michigan Department of Natural Resources, Fisheries Management. Report 6, Lansing.

Thompson, D. E. 1970. The first fifty years-the exciting ones. Pages 1-11 in N. G. Benson, ed. A century of fisheries in North America. American Fisheries Society Special Publication 7.

Westerman, F. A., and A. S. Hazzard. 1945. For better fishing! Michigan Conservationist $14(7,8,9,10)$.

Westers, H., and T. M. Stauffer. 1974. A history of fish culture in Michigan. Pages 107-125 in Michigan Fisheries Centennial Report 1873-1973. Michigan Department of Natural Resources. Fisheries Management Report 6, Lansing.

Wood, E. M. 1953. A century of fish culture, 1853-1953. The Progressive Fish-Culturist 15(4):147-162. 